\title{
Knowledge, Attitude, and Practice on Menstrual Hygiene Management among School Adolescents
}

\author{
Ram Naresh Yadav, ${ }^{1}$ Shrijana Joshi, ${ }^{1}$ Rajesh Poudel, ${ }^{1}$ Pawan Pandeya ${ }^{1}$ \\ ${ }^{1}$ Public Health, Good Neighbors International, Nepal.
}

\begin{abstract}
Background: Menstrual hygiene management remains a taboo in many communities in Nepal. Cultural beliefs about menstruation such as food taboos and untouchability have negative impact on dignity, health and education of adolescent girls. The objective of the study was to assess the current knowledge, attitude and practice of school adolescents on menstrual hygiene management in Doti District in Far-Western Nepal.

Methods: This cross-sectional study was carried out from October to December 2016 at seven village development committees in Doti district, Nepal. This study was done among 276 students from grade seven and eight of 11 schools. Self-administered structured questionnaire was used to obtain information from school students. Descriptive analysis was done to analyse the knowledge, attitude and practice of school adolescents on menstrual hygiene management.

Results: $67.4 \%$ respondents had fair knowledge and 26.4\% respondents had good knowledge on menstrual hygiene management. However, out of 141 female adolescent respondents, only $56(40 \%)$ were engaged in good menstrual hygiene practices. Around half of the respondents had positive attitude towards menstrual hygiene management related issues.

Conclusions: Although knowledge on menstrual hygiene management among school adolescents is fair, still attitude and practice need to improve. Findings indicate the need of behavior change communication campaigns along with frequent reinforcement of school health education programs.

Keywords: Knowledge; attitude; practice; menstrual hygiene management .
\end{abstract}

\section{INTRODUCTION}

Menstruation, that starts with the onset of puberty, is a physiological process in females. ${ }^{1}$ Nepali society has viewed it as a religiously impure and culturally shameful occurrence. "Chhaupadi" is a traditional practice in which females are forbidden to touch anything and are forced to live in isolation (shed) during menstruation. ${ }^{3}$ The situation is not different in Far West region, with reported incidents of rapes and physical assaults while in Chhaupadi. ${ }^{4}$ Such practices have caused adverse effect on females' capacity to manage their periods. ${ }^{5-6}$

These problems are further exacerbated by insufficient access to clean toilets, water and soap. ${ }^{7,8}$ These are vital factors leading to absenteeism as high as $53 \%$ of girls in Nepal. ${ }^{8-11}$ Also, comprehensive awareness raising at schools is vital for promoting Menstrual hygiene management (MHM). ${ }^{12,13}$ The main purpose of the study was to evaluate knowledge, attitude and practices of school adolescents regarding MHM in Doti district.

\section{METHODS}

Doti district in Nepal is reported to have high prevalence of "Chhaupadi" and significantly low access to and use of MHM services. Thus, a cross-sectional study was carried out from October to December 2016 at seven village development committees (VDCs) in Doti district, Nepal. The sample size of 276 was obtained with the assumption that the practice should be about 53\% in our population of respondents. Students were selected randomly from grade seven and eight of 11 schools.

Respondents' KAP were measured by using a set of nine knowledge related questions, 12 practice related
DOI: http://dx.doi.org/10.3126/
inhrc.v15i3.18842

Correspondence: Ram Naresh Yadav, Public Health, Good Neighbors

International Nepal. Email: ram.naresh@gninepal.org, Phone : +977

9855026454. 
questions and eight attitude related statements. The topics to be included in the questionnaire were developed on the basis of a thorough review of literature and the authors' experience of important issues related to menstrual hygiene management in Nepal. The scores for knowledge and practice items were given one for each correct answer and a score of zero for an incorrect answer. Later all score were summed up and classified into three categories, good (more than $80 \%$ score), fair (69\%-79\% score) and poor (below 69\% score). Similarly, all the attitude statements were measured in three point Likert scale ranging from disagree, don't know and agree. A score of one was given for correct statement and zero for don't know or wrong statement. Later, all score were summed up and classified into two categories, positive attitude (more than $80 \%$ score) and need improvement (below $80 \%$ score). Self-administered structured questionnaire was used to obtain information from school students.

The study period of this study was from October 1 to December 28, 2016. Data collection was carried out at the schools during school hours with due verbal consent from respective school principals. Eligible participants were explained the purpose of the study and method of completing the questionnaire and took affirmation from the respondents to participate in the study. Approval for this study was obtained from ethical review board of Nepal Health Research Council. Data was analyzed using MS-Excel and SPSS version 22.

\section{RESULTS}

Only four out of 11 schools had a separate toilet available for students and teachers. Seven schools had gender-friendly toilets. Only three schools had running water available in the toilets but only one school had the availability of soap for washing hands in the toilet. At the time of observation, marks of open urination/ defecation were found in four schools. None of the schools had mirror available at toilets. Rest room for use during menstruation was not available in any of the schools. Only five schools had enough drinking water for students during school time.

About the knowledge on Menstruation Hygiene Management, $17(6.2 \%)$ of the respondents had poor knowledge, $186(67.4 \%)$ had fair knowledge and 73 (26.4\%) had good knowledge of menstrual hygiene management. $83 \%$ of the respondents agreed that menstruation is a physiological process. $44 \%$ of the respondents wereaware of the age of menarche and $70 \%$ knew the age of menopause. $90 \%$ of the participants were aware of the reason to use sanitary pad. $35 \%$ of the participants were of the opinion that time interval to change pad is daily. $97 \%$ of respondents knew the reason for washing hands after handling used pad and $98.9 \%$ of respondents knew about the proper way of disposing used pad.

\begin{tabular}{|lr|}
\hline Table 1. Knowledge regarding MHM. & \\
\hline Variables (276) & Number (\%) \\
\hline Menstruation & $229(83)$ \\
\hline Physiological process & $3(1.1)$ \\
\hline Curse from god & $29(10.5)$ \\
\hline Untouchability & $1(.4)$ \\
\hline Disease & $14(5.1)$ \\
\hline Don't know & \\
\hline Reason to use sanitary pad & $250(90.6)$ \\
\hline Manage blood flow and maintain & \\
\hline hygiene & $7(2.5)$ \\
\hline To relieve pain & $5(1.8)$ \\
\hline Instead of taking shower & $14(5.1)$ \\
\hline Don't know & \\
\hline Time interval to change pad & $40(28)$ \\
\hline Every hour & $29(21)$ \\
\hline Every 4-6 hours & $49(35)$ \\
\hline Daily & $23(16)$ \\
\hline Don't know & $116(42)$ \\
\hline Way to dispose of used pad & \\
\hline Burning & $106(38.4)$ \\
\hline Burying & $51(18.5)$ \\
\hline Throw away & $36.1 \%)$ \\
\hline Both a or b & \\
\hline Knowledge (Summary index) & \\
\hline Poor knowledge & \\
\hline Fair knowledge & \\
\hline Good knowledge & \\
\hline On the & \\
\hline
\end{tabular}

On the practices related to menstruation, out of 141 female adolescent respondents, 56 (40\%) had good menstrual hygiene practices. 72 (51\%) girls had a fair practice and 13 (9\%) had poor menstrual hygiene practices.

$30 \%$ of the respondents used factory made sanitary pads followed by $76 \%$ of them using homemade and reusable pads. However, only $39 \%$ of respondents changed pads in every 4-6 hour period. $68 \%$ of the respondents washed hands after changing a sanitary pad and $61 \%$ used soap and water for washing hands. 


\begin{tabular}{|c|c|}
\hline Parameters of practice & Number (\%) \\
\hline $\begin{array}{l}\text { Uses commercially made sanitary pad as } \\
\text { absorbent during menstruation }\end{array}$ & $30(21.3 \%)$ \\
\hline Uses home made reusable pad & $76(53.9 \%)$ \\
\hline $\begin{array}{l}\text { Changing pad every } 4-6 \text { hours during } \\
\text { menstruation }\end{array}$ & $39(27.7 \%)$ \\
\hline Washes hands after changing pad & $96(68.1 \%)$ \\
\hline $\begin{array}{l}\text { Uses soap water to wash hands after } \\
\text { pad change }\end{array}$ & $86(61.4 \%)$ \\
\hline $\begin{array}{l}\text { Clean genitalia after every toilet visit } \\
\text { during menstruation }\end{array}$ & $84(59.6 \%)$ \\
\hline Clean genitalia after pad change & $79(56 \%)$ \\
\hline Change underwear during changing pad & $64(45.4 \%)$ \\
\hline $\begin{array}{l}\text { Clean genitalia in front to back motion } \\
\text { during menstruation }\end{array}$ & $56(39.7 \%)$ \\
\hline $\begin{array}{l}\text { Properly manages used pads during } \\
\text { menstruation }\end{array}$ & $96(67.4)$ \\
\hline Takes bath daily during menstruation & $111(78.7 \%)$ \\
\hline Use school toilet during menstruation & $127(90.1 \%)$ \\
\hline \multicolumn{2}{|l|}{ Practice (summary index) } \\
\hline Good practice & $56(40 \%)$ \\
\hline Fair practice & $72(51 \%)$ \\
\hline Poor practice & $13(9 \%)$ \\
\hline
\end{tabular}

$136(49 \%)$ of the respondents had a positive attitude towards MHM issues whereas 140 (51\%) required improvement on their attitude towards MHM. Data showed that $52.5 \%$ of the respondents agreed restrictions for carrying out household chores during menstruation is significant. Only $47 \%$ thought that violation or nonobservance of cultural traditions and taboos during menstruation will not lead to god or deities cursing their family members. $77 \%$ of respondents agreed that, increase in supplementation of nutrients/food is necessary during menstruation. Only $54 \%$ of respondents thought that men do not become sick if a menstruating female touches him. $65 \%$ of respondents agreed that menstruating females should take bath. Only $45 \%$ of respondents agreed that menstruating females can consume dairy and sour food items.

\section{Table 3. Attitude Regarding MHM.}

\section{Statements}

Number

(\%)

Restriction in household task during menstruation is not significant

Self-esteem increases after menarche
Menarche signals the body is

functioning normally

God will not curse family members

if cultures/ taboos are not followed

during menstruation

Increase in supplementation of

nutritious food is necessary during

menstruation

Men will not become sick when

menstruating female touch them

Menstruating female should take bath

Menstruating females can eat dairy and 123 (44.6\%) sour items

Positive attitude

Need improvement

$140(51 \%)$

In regards to accessibility of MHM and Water, Sanitation \& Hygiene (WASH) facilities and services, $47.5 \%$ of respondents first heard about menstruation at the age 10-12 years mostly getting information on menstruation from school additionally followed by friends, mother, and guardian. Over $70 \%$ of respondents had heard message on menstruation from the local radio station. About $45 \%$ of respondents had not got any MHM education class/orientation. Data showed that NGOs are mainly providing MHM education/orientation/training in school. Only $28.3 \%$ of female respondents had ever participated in a sanitary pad making training and $27.2 \%$ had made reusable sanitary pads after participating in the training. About $70 \%$ respondents replied unavailability of supplies for managing menses at school.

Different questions about their belief, tradition and culture related to menstruation were asked to adolescent girls and boys. Among a total of 141 female respondents, $39 \%$ responded 'feeling shame to talk about menstrual status' followed by pain and then by leaks, stains, and menstruation related odor leading to teasing by boys as major challenges faced during menstruation. Although knowledge score was high, more than half of female respondents stayed at a separate room at their home during menstruation and were not allowed to participate in cultural/religious functions. Not surprisingly, only 29 respondents said they got psychological support from their family during menstruation. Thus, findings indicate the need of behavior change communication campaigns along with frequent reinforcement of school health education programs. 


\section{DISCUSSIONS}

Our results show that most of school adolescents have fair knowledge on menstrual hygiene management, although there is still considerable scope for improvement of hygiene related practices and attitude on taboos related to menstruation.

Findings showed that $83 \%$ of respondents had the idea that menstruation is a physiological process, which is significantly higher than findings from other studies. ${ }^{5,14}$ Majority of respondents knew the reason to use sanitary pad during menstruation which is in contrast with finding of study conducted by Dasgupta in which just $48.75 \%$ knew the use of sanitary pad. ${ }^{15}$ This increment in knowledge indicates exposure and readiness of school adolescents to adopt hygiene behavior. Though majority of students know about menstruation which might be attributed to the inclusion of reproductive health education in school curricula and exposure to a wide range of information media like television, radio, internet; still misperceptions persist in this matter. More than $50 \%$ still believed that god will curse family members if they do not follow cultures/taboos associated with menstruation. This is supported by the study of Adhikari et al who mentioned females would sprinkle gold water to purify themselves. ${ }^{16}$ Additionally, it was also discovered that boys tease their female peers during menstruation which creates an environment of shame and fear among adolescent girls. Previous studies have also revealed a higher proportion of respondents considering menstruation to be inconvenient and embarrassing. ${ }^{16}$

Promotion of adolescent sexual and reproductive health and prevention of diseases are among the key reasons for menstrual hygiene. Our study found that majority of school girls used sanitary pads (commercial or reusable) during their menstruation. This is similar to reports from Lawan and colleagues from Nigeria ${ }^{17}$ but in contrast to the study conducted in India ${ }^{15}$ and Adinma's study where the majority was found to be using toilet rolls to manage menstrual blood. ${ }^{18}$ Data showed that only $40 \%$ of the respondents had a good level of menstruation hygiene management practices followed fair practices with $51 \%$ girls, and nine percent had adopted a poor set of practices. Findings show a gap between existing knowledge and practice which is in concurrence with other findings. ${ }^{5}$ One of the possible hindrances could be lack of availability of sanitary pads in rural setting to adopt proper hygienic menstruation practice along with lack of disposal facilities.

In accordance to the findings from our study, 55.4\% believed menstruating females should not consume poultry and sour food items. These findings on food taboos agreed with another study conducted in rural Nepal. ${ }^{5}$ Despite of expanding knowledge horizon, cultural taboos existing in society is preventing change in attitude; hence practice on menstrual hygiene management among school students. This situation demonstrates dire need to address the harmful practices in the name of culture.

\section{CONCLUSIONS}

The results indicate that majority of the respondent girls have knowledge of MHM but it hasn't clearly translated into the right attitude and practice, hence, behavior change programs should be conducted in those communities. Massive advocacy campaigns are also required to combat the deeply ingrained religious and cultural malpractices, restrictions, and taboos related to menstruation. Interventions to increase access to hygienic absorbents and disposal of MHM items are the issues that should be addressed. School WASH facilities are currently acutely inadequate for the girls to safely manage their menses; enough water is not available, gender friendly toilets, both for students and teachers are missing and hand washing facilities are absent. Hence, MHM friendly WASH infrastructures and facilities must be created at schools.

\section{REFERENCES}

1. Archibald AB, Graber JA, Brooks-Gunn J. Pubertal processes and physiological growth in adolescence. Blackwell Handbook of Adolescence. 2003:24-47.

2. Ranabhat C, Kim CB, Choi EH, Aryal A, Park MB, Doh YA. Chhaupadi culture and reproductive health of women in Nepal. Asia Pac J Pub Health. 2015 Oct;27(7):785-95. [PubMed]

3. Amgain B. Social dimension of Chhaupadi system: A study from Achham district, Far west Nepal. Social Inclusion Research Fund (SIRF). 2012 Aug 8. [Link]

4. Dahal K. Nepalese woman dies after banishment to shed during menstruation. BMJ. 2008 Nov 14;337.[PubMed]

5. Sapkota D, Sharma D, Pokharel HP, Budhathoki SS, Khanal VK. Knowledge and practices regarding menstruation among school going adolescents of rural Nepal. J Kathmandu Med Coll. 2014 Mar 3;2(3):122-8. [Full Text]

6. UNESCO. 2014. Puberty education and menstrual hygiene management. Paris, UNESCO [Full Text] 
7. Sara J, Fritz W. Meeting women's needs and priorities for water and sanitation in cities. Environment and Urbanization. 1993;5(2):135-145. [Full Text]

8. Issa M, McHenry M, Issa AA, Blackwood RA. Access to safe water and personal hygiene practices in the Kulandia Refugee Camp (Jerusalem). Infect Dis Rep. 2015 Dec 22; 7(4).[PubMed]

9. Nepal Fertility Care Center: Menstrual Hygiene Management. [cited 2017 January]. [Full Text]

10. WaterAid Ethiopia/ UNICEF/ VSO. Sanitation provision in Benshangul-Gumuz Region State (BGRS) Schools: girls and women's experiences. 2005

11. Crofts T, Fisher J. Menstrual hygiene in Ugandan schools: an investigation of low-cost sanitary pads. Journal of Water Sanitation and Hygiene for Development. 2012;2(1):508.[Full Text]

12. Ndlovu E, Bhala E. Menstrual hygiene-a salient hazard in rural schools: a case of Masvingo district of Zimbabwe: original research. Jàmbá: Journal of Disaster Risk Studies. 2016 Jan 1;8(2):18. [Full Text]

13. Rizvi N, Ali TS. Misconceptions and Mismanagement of Menstruation among Adolescents Girls who do not attend School in Pakistan. Journal of Asian Midwives. 2016;3(1):46-62. [Full Text]
14. Juyal R, Kandpal SD, Semwal J, Negi KS. Practices of menstrual hygiene among adolescent girls in a district of Uttarakhand. Indian Journal of Community Health. 2012 Jul 19;24(2):124-8. [Full Text]

15. Dasgupta A, Sarkar M. Menstrual hygiene: How hygienic is the adolescent girl? Indian J Community Med. 2008 Apr;33(2):77.[PubMed]

16. Adhikari P, Kadel B, Dhungel SI, Mandal A. Knowledge and practice regarding menstrual hygiene in rural adolescent girls of Nepal. Kathmandu Univ Med J. 2006 Dec;5(3):382-6.[PubMed]

17. Lawan UM, Nafisa WY, Musa AB. Menstruation and menstrual hygiene amongst adolescent school girls in Kano, Northwestern Nigeria. Afr J Reprod Health. 2010 Sep 1;14(3):201-7.[PubMed]

18. Adinma ED, Adinma JI. Perceptions and practices on menstruation amongst Nigerian secondary school girls. Afr J Reprod Health. 2008;12(1):74-83.[PubMed] 